EPJ Web of Conferences 92, 02104 (2015)

DOI: $10.1051 /$ epjconf/ 20159202104

(C) Owned by the authors, published by EDP Sciences, 2015

\title{
Dynamical behaviour of three-way throttle valve with pressure gradient stabilization
}

\author{
Martin Vašina ${ }^{1, a}$, Lumír Hružík ${ }^{1}$, Adam Bureček ${ }^{1}$ and Roman Sikora ${ }^{1}$ \\ ${ }^{1}$ VŠB-Technical University of Ostrava, Faculty of Mechanical Engineering, Department of Hydromechanics and Hydraulic \\ Equipment, 70833 Ostrava, Czech Republic
}

\begin{abstract}
Three-way throttle valves with pressure gradient stabilization are used in order to ensure constant flow independently of load changes of hydraulic motors in hydraulic systems. These valves are used to vibration damping in hydraulic systems too. For this reason, it is suitable to install the valves close to hydraulic motors. The valves also have a positive influence on an increasing of system eigenfrequency. The paper deals with investigation of dynamical behaviour and eigenfrequency of a three-way throttle valve with pressure gradient stabilization in consequence of transient changes.
\end{abstract}

\section{Introduction}

Ordinary throttle valves are variable resistance elements that are applied to flow control. Liquid flow $Q$ through the throttle valve is given by the equation [1]:

$$
Q=S \cdot \mu \cdot \sqrt{\frac{2 \cdot \Delta p}{\rho}}
$$

where $S$ is throttle cross-section of the valve, $\mu$ is flow coefficient $(\mu=0.68 \div 0.78), \Delta p$ is pressure gradient through the valve and $\rho$ is liquid density.

It is evident from the Eq. (1) that the flow through the throttle valve is inversely proportional to the pressure gradient. In case of a load change of a hydraulic motor, the pressure gradient is changed. For this reason the flow through the valve is changed too. It is a big disadvantage of these valves. Furthermore, pressure losses of the throttle valves are relatively large.

Three-way throttle valves with pressure gradient stabilization are hydraulic elements that are used in order to ensure constant flow. For this reason velocity (or speed) of hydraulic motors is constant independently of load changes.

The aim of the paper is to investigate dynamical properties and eigenfrequency of three-way throttle valve with pressure gradient stabilization in terms of transient changes.

\section{Principle of three-way throttle valve}

A schematic diagram of a hydraulic system including three-way throttle valve with pressure gradient stabilization is shown in figure 1 . The three-way throttle

${ }^{\mathrm{a}}$ Corresponding author: martin.vasina@vsb.cz valve 3 -TV is located in front of the rotary hydraulic motor HM. It consists of the throttle valve TV and the pressure reducing valve PRV. These valves are connected in parallel [2]. The constant flow hydraulic pump HP with the liquid flow $Q_{1}$ is a source of pressure energy. The relief valve $\mathrm{RV}$ is used to system protection against overload. A size of the flow $Q_{2}$ to the hydraulic motor is controlled by the throttle valve. It remains practically constant independently of load changes. The excessive flow $Q_{T}$ through the pressure reducing valve is given by the difference between the input flow $Q_{1}$ and the output flow $Q_{2}$.

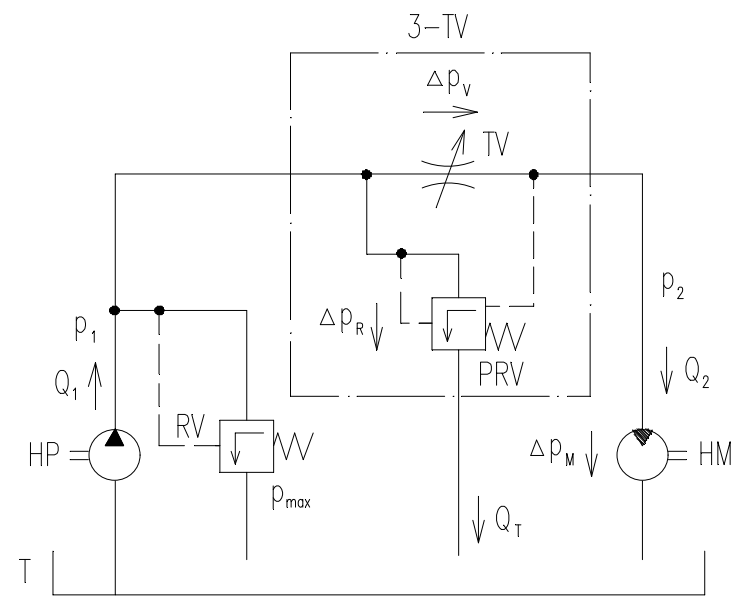

Figure 1. Schematic diagram of hydraulic system with threeway throttle valve and pressure gradient stabilization.

The working principle of the three-way throttle valve with pressure gradient stabilization (type SP 12L30/TD $250 \mathrm{RM} 01$ ) is shown in figure 2. The throttle valve is 
replaced by the proportional distributor PD in this case [3]. An actual pressure signal $p_{2}$ from a motor load is fed through the logical valve LV into one side of the slide valve of the pressure reducing valve PRV. The input pressure $p_{1}$ is fed into the other side of the slide valve. The hydraulic resistance of the pressure reducing valve is decreasing with decreasing the motor load. For this reason the valve permeability is increasing. Similarly, the hydraulic resistance of the valve is increasing with increasing the motor load and the valve permeability is decreasing in this case. The pressure gradient through the proportional distributor is practically constant (i.e. $\Delta p_{v}=1 \div 2 \mathrm{MPa}$ ) during control of the pressure reducing valve. The cross section of the investigated pressure reducing valve [4] is shown in Figure 3.

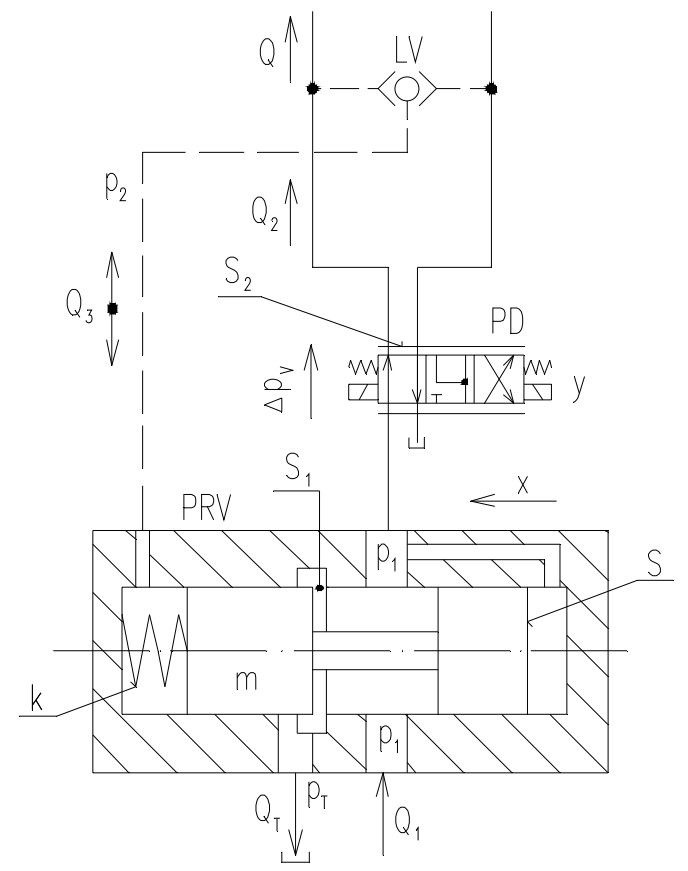

Figure 2. Schematic diagram of working principle of three-way throttle valve with pressure gradient stabilization.

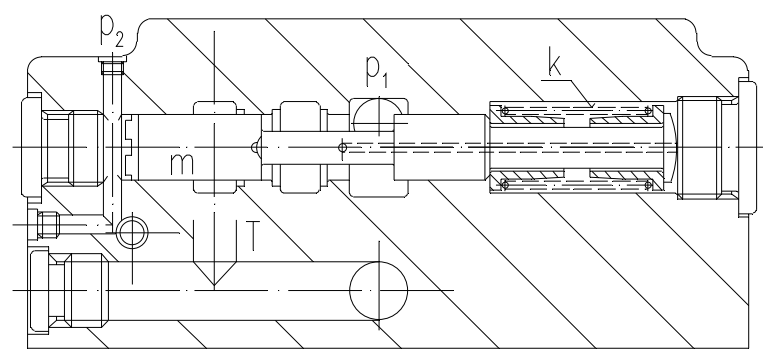

Figure 3. Cross section of pressure reduction valve.

The equilibrium of forces with respect to the moving slide valve of the valve PRV in the $x$ direction (see figure 2) is expressed by the equation:

$$
m \cdot \frac{d^{2} x}{d t^{2}}+b \cdot \frac{d x}{d t}+k \cdot x=\left(p_{1}-p_{2}\right) \cdot S
$$

where $m$ is mass of the slide valve ( $m=0.21 \mathrm{~kg}), b$ is damping coefficient of the slide valve (commonly $\left.b=100 \mathrm{~N} \cdot \mathrm{s} \cdot \mathrm{m}^{-1}\right), k$ is spring rate $\left(k=15329 \mathrm{~N} \cdot \mathrm{m}^{-1}\right)$ and $S$ is cross-sectional area of the slide valve $\left(S=2.54 \cdot 10^{-4}\right.$ $\left.\mathrm{m}^{2}\right)$ [3].

The flow $Q$ into a hydraulic motor depends on a load change of the motor and is given by the formula:

$$
Q=Q_{2} \pm Q_{3},
$$

where $Q_{2}$ is linearized flow through the proportional distributor and $Q_{3}$ is flow above the slide valve of the pressure reducing valve. These flows are expressed by the following formulas [3]:

$$
\begin{gathered}
Q_{2}=S_{v} \cdot y+Z_{v} \cdot\left(p_{1}-p_{2}\right), \\
Q_{3}=S \cdot \frac{d x}{d t},
\end{gathered}
$$

where $S_{v}$ is sensitivity of the proportional distributor $\left(S_{v}=0.011 \mathrm{~m}^{2} \cdot \mathrm{s}^{-1}\right), y$ is displacement of the slide valve of the distributor and $Z_{v}$ is leakage permeability of the distributor $\left(Z_{v}=1.2 \cdot 10^{-11} \mathrm{~N}^{-1} \cdot \mathrm{m}^{5} \cdot \mathrm{s}^{-1}\right)$.

The linearized flow $Q_{T}$ through the pressure reducing valve having the throttle cross-section $S_{1}$ (see figure 2) into the tank is described by the equation [3]:

$$
Q_{T}=S_{T} \cdot x+Z_{T} \cdot p_{1}
$$

where $S_{T}$ is sensitivity of the pressure reducing valve $\left(S_{T}=6.22 \mathrm{~m}^{2} \cdot \mathrm{s}^{-1}\right)$, and $Z_{T}$ is leakage permeability of the pressure reducing valve $\left(Z_{T}=6.4 \cdot 10^{-10} \mathrm{~N}^{-1} \cdot \mathrm{m}^{5} \cdot \mathrm{s}^{-1}\right)$.

The values of the above-mentioned quantities were experimentally determined [3] in terms of geometry of the three-way throttle valve with pressure gradient stabilization and the oil density $\rho=828 \mathrm{~kg} \cdot \mathrm{m}^{-3}$.

\section{Dynamical behaviour of three-way throttle valve with pressure gradient stabilization}

The dynamical behaviour of the investigated threeway throttle valve with pressure gradient stabilization during movement of the slide valve (see figure 2 and figure 3 ) to the left (i.e. due to decrease of motor load or by reason of decrease of the throttle cross-section $S_{2}$ of the proportional distributor) is described by the following equations [4]:

$$
\begin{gathered}
m \cdot \frac{d^{2} x}{d t^{2}}+b \cdot \frac{d x}{d t}+k \cdot\left(x_{0}+x\right)=\left(p_{1}-p_{2}\right) \cdot S, \\
Q_{1}=S_{T} \cdot x+Z_{T} \cdot p_{1}+Q=\text { const. } \\
Q=S_{v} \cdot y+Z_{v} \cdot\left(p_{1}-p_{2}\right)+S \cdot \frac{d x}{d t},
\end{gathered}
$$

where $x_{0}$ is initial spring compression $\left(x_{0}=23.2 \mathrm{~mm}\right)$ and $Q_{1}$ is input flow from the hydraulic pump.

Similarly in case of the slide movement to the right (i.e. due to increase of motor load or by reason of increase of the throttle cross-section $S_{2}$ of the 
proportional distributor), the dynamical behaviour of the three-way throttle valve is expressed by the equations [4]:

$$
\begin{gathered}
m \cdot \frac{d^{2} x}{d t^{2}}+b \cdot \frac{d x}{d t}+k \cdot x=\left(p_{2}-p_{1}\right) \cdot S+k \cdot x_{0}, \\
Q_{1}=-S_{T} \cdot x+Z_{T} \cdot p_{1}+Q=\text { const. } \\
Q=S_{v} \cdot y+Z_{v} \cdot\left(p_{1}-p_{2}\right)-S \cdot \frac{d x}{d t} .
\end{gathered}
$$

\subsection{Simulation of dynamical behaviour for throttling of proportional distributor}

Dynamical properties of the three-way throttle valve with pressure gradient stabilization were investigated using Mathcad software and by the Laplace transformation. There are considered only dynamical (i.e. non-constant) quantities in mathematical simulations [3].

\subsubsection{Simulation of dynamical behaviour using Mathcad software}

Mathematical simulation of dynamical behaviour of the three-way throttle valve with pressure gradient stabilization was firstly performed for the throttling (i.e. $\Delta y=-1.5 \mathrm{~mm}$ ) of the slide valve of the proportional distributor. There were supposed constant values of the input flow $Q_{1}$ and the pressure $p_{2}$ in these simulations. For this reason the Eqs. (7) $\div$ (9) are modified as follows:

$$
\begin{gathered}
m \cdot \frac{d^{2} x}{d t^{2}}+b \cdot \frac{d x}{d t}+k \cdot x=p_{1} \cdot S, \\
0=S_{T} \cdot x+S_{v} \cdot y+\left(Z_{v}+Z_{T}\right) \cdot p_{1}+S \cdot \frac{d x}{d t} .
\end{gathered}
$$

On the basis of a mathematical treatment of the above-mentioned equations, it is possible to express the differential equation of the position change of the slide valve of the pressure reducing valve depending on the throttling of the proportional distributor:

$$
\begin{gathered}
\frac{d^{2} x}{d t^{2}}=-\frac{1}{m} \cdot\left(b+\frac{S^{2}}{Z_{v}+Z_{T}}\right) \cdot \frac{d x}{d t}- \\
-\frac{1}{m} \cdot\left(k+\frac{S \cdot S_{T}}{Z_{v}+Z_{T}}\right) \cdot x-\frac{S_{v} \cdot S \cdot y}{m \cdot\left(Z_{v}+Z_{T}\right)} .
\end{gathered}
$$

The Eq. (15) was solved by the Runge-Kutta $4^{\text {th }}$ order method using Mathcad software [5]. As a result of these simulations, the time dependencies of the position $x$ and the velocity $v=d x / d t$ of the slide valve of the pressure reducing valve are shown in figure 4 and figure 5 . The slide valve of the pressure reducing valve is in a new steady-state position after the time $t \cong 0.01 \mathrm{~s}$ (see figure 4 and figure 5) in consequence of the transient change.

The time dependence of the input pressure $p_{1}$ (see figure 6) is determined from the Eq. (14):

$$
p_{1}=-\frac{1}{Z_{v}+Z_{T}} \cdot\left(S_{T} \cdot x+S_{v} \cdot y+S \cdot \frac{d x}{d t}\right) .
$$

Similarly, the output flow $Q$ (see figure 7) can be expressed from the Eq. (9):

$$
Q=S_{v} \cdot y+Z_{v} \cdot p_{1}+S \cdot \frac{d x}{d t} .
$$

It is obvious that throttling of the proportional distributor gives rise to a reduction of the input flow (see figure 7).

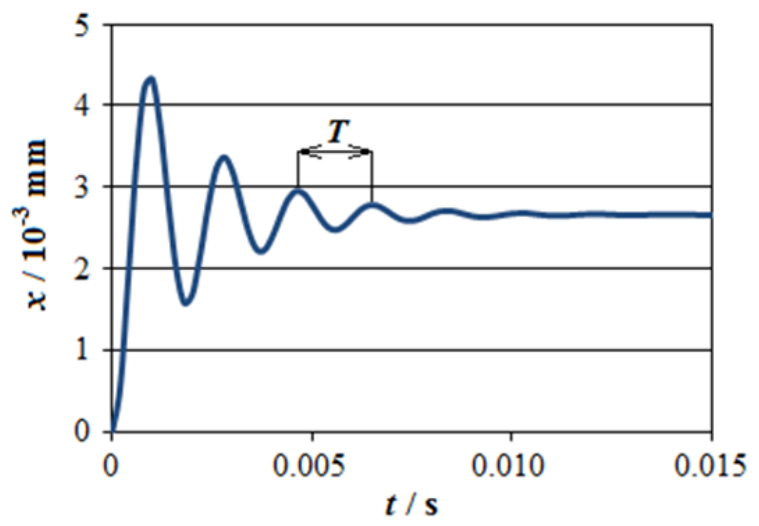

Figure 4. Time dependence of position of slide valve of pressure reduction valve.

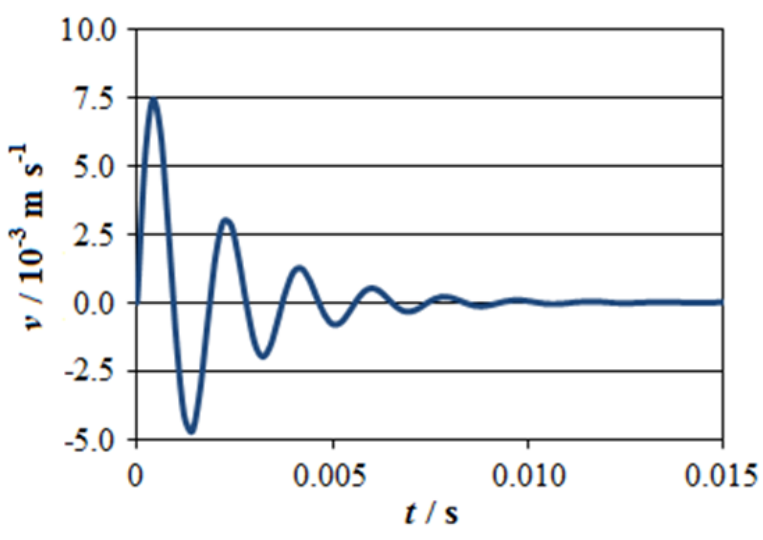

Figure 5. Time dependence of velocity of slide valve of pressure reduction valve.

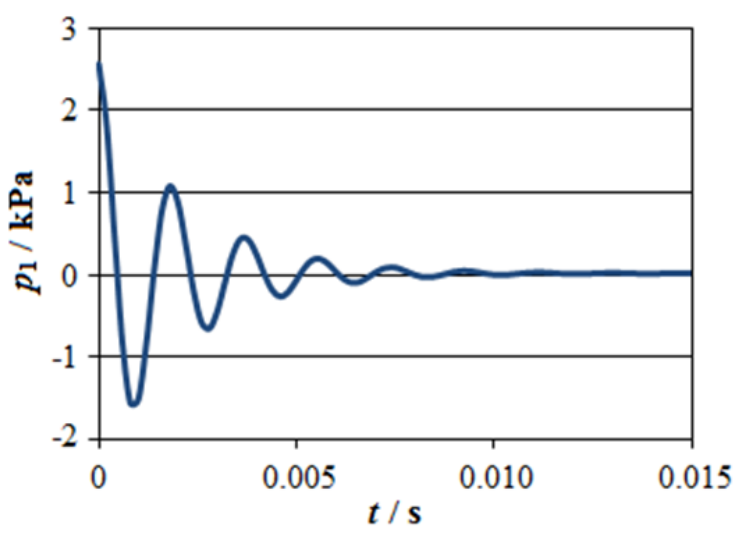

Figure 6. Time dependence of input pressure. 


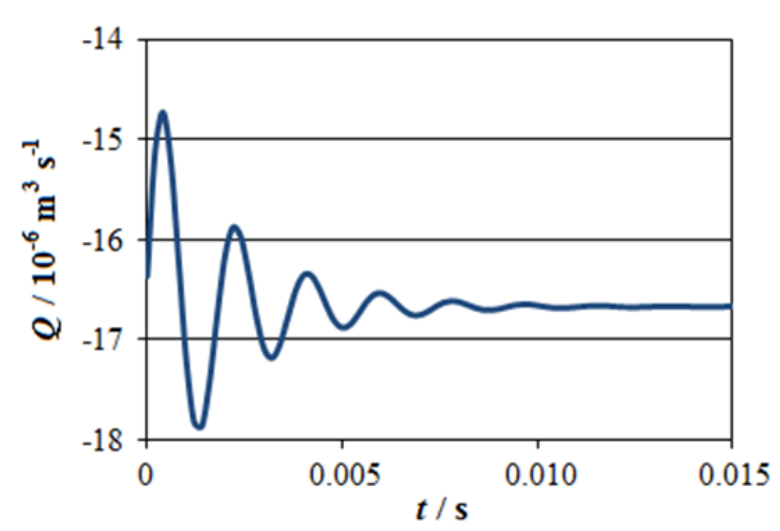

Figure 7. Time dependence of output flow.

It is evident (see figure $4 \div$ figure 7 ), that the simulated time dependencies are damped periodic with the period of oscillation $T \cong 0.0018$ s (see Figure 4), which is proportional to the eigenfrequency $f_{0}$ :

$$
f_{0}=\frac{1}{T} \cong 555.6 \mathrm{~Hz}
$$

\subsubsection{Determination of eigenfrequency by Laplace transformation}

It is possible to obtain more accurate values of the period of oscillation and the eigenfrequency by the Laplace transformation. The Laplace image $F(s)$ of the time function $f(t)$ is defined by the formula $[6,7]$ :

$$
F(s)=L\{f(t)\}=\int_{0}^{\infty} e^{-s \cdot t} \cdot f(t) d t,
$$

where $s$ is parameter of the Laplace transformation. The transfer function $F_{y x}(s)$ of a system is equal to its transpose [8]:

$$
F_{y x}(s)=\frac{L\{y(t)\}}{L\{x(t)\}}=\frac{Y(s)}{X(s)}=\frac{g(s)}{G(s)},
$$

where $Y(s)$ is Laplace image of an output quantity $y, X(s)$ is Laplace image of an input quantity $x, g(s)$ is numerator of the transfer function and $G(s)$ is denominator of the transfer function. If the denominator $G(s)=0$, it is possible to determine the transfer function poles $s_{k}$ :

$$
s_{k}=\alpha_{k} \pm i \cdot \omega_{k},
$$

where $\alpha_{k}$ is real part of transfer function poles, $i$ is imaginary unit and $\omega_{k}$ is imaginary part of transfer function poles. The system eigenfrequency $f_{0}$ can be subsequently determined from the equation:

$$
f_{0}=\frac{\omega_{k}}{2 \cdot \pi}
$$

After Laplace transforming, the Eqs. (13) and (14) are modified as follows:

$$
\begin{gathered}
m \cdot s^{2} \cdot X(s)+b \cdot s \cdot X(s)+k \cdot X(s)=P_{1}(s) \cdot S \\
0=S_{T} \cdot X(s)+S_{v} \cdot Y(s)+ \\
+\left(Z_{v}+Z_{T}\right) \cdot P_{1}(s)+S \cdot s \cdot X(s)
\end{gathered}
$$

In this case, the transfer function $F_{P 1 Y}$ is given by the ratio of the Laplace image $P_{1}(\mathrm{~s})$ of the input pressure and the Laplace image $Y(\mathrm{~s})$ of the slide valve position of the proportional distributor. It is possible to determine the transfer function $F_{P 1 Y}$ from the Eqs. (23) and (24):

$$
F_{P_{1} Y}(s)=\frac{P_{1}(s)}{Y(s)}=\frac{-S_{v} \cdot\left(m \cdot s^{2}+b \cdot s+k\right)}{s^{2} \cdot s+S_{T} \cdot S+\left(Z_{v}+Z_{T}\right) \cdot\left(m \cdot s^{2}+b \cdot s+k\right)}
$$

If the denominator value of the Eq. (25) is equal to zero, then the obtained transfer function poles $s_{k}=-475.724 \pm 3382 i$. For this reason the eigenfrequency of the investigated three-way throttle valve with pressure gradient stabilization is determined as follows:

$$
f_{0}=\frac{3382}{2 \cdot \pi}=538.26 \mathrm{~Hz}
$$

\subsection{Simulation of dynamical behaviour for step increase in load}

\subsubsection{Simulation of dynamical behaviour using Mathcad software}

Mathematical simulation of dynamical behaviour of the investigated three-way throttle valve was also performed for the step increase of the output pressure (i.e. $\Delta p_{2}=5 \mathrm{MPa}$ ). There are supposed constant values of the input flow $Q_{1}$ and the position $y$ of the slide valve of the proportional distributor. Then the Eqs. (10) $\div$ (12), describing the dynamical behaviour of the step increase in load, are modified in the following manner:

$$
\begin{gathered}
m \cdot \frac{d^{2} x}{d t^{2}}+b \cdot \frac{d x}{d t}+k \cdot x=\left(p_{2}-p_{1}\right) \cdot S, \\
0=-S_{T} \cdot x+Z_{T} \cdot p_{1}+Z_{v} \cdot\left(p_{1}-p_{2}\right)-S \cdot \frac{d x}{d t} .
\end{gathered}
$$

The differential equation of the position change of the slide valve of the pressure reducing valve depending on the output pressure is obtained from the Eqs. (27) and (28) as follows:

$$
\begin{aligned}
& \frac{d^{2} x}{d t^{2}}=-\frac{1}{m} \cdot\left(b+\frac{S^{2}}{Z_{v}+Z_{T}}\right) \cdot \frac{d x}{d t}- \\
& -\frac{1}{m} \cdot\left(k+\frac{s \cdot S_{T}}{Z_{v}+Z_{T}}\right) \cdot x+\frac{p_{2} \cdot s \cdot Z_{T}}{m \cdot\left(Z_{v}+Z_{T}\right)} .
\end{aligned}
$$

The time dependencies of the position $x$ and the velocity $v$ of the slide valve of the pressure reducing valve for the step change of the output pressure $p_{2}$ are shown in figure 8 and figure 9 . It is evident, that the slide valve is moved to a new position by reason of the pressure change. 


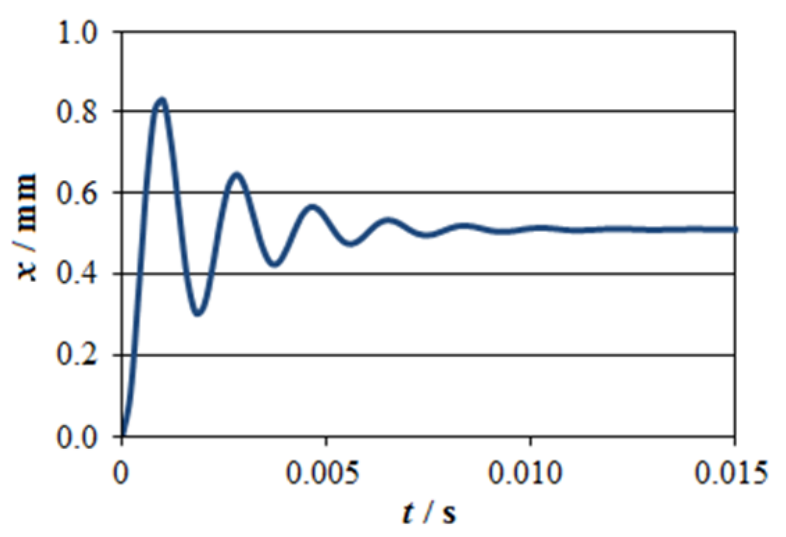

Figure 8. Time dependence of position of slide valve of pressure reduction valve.

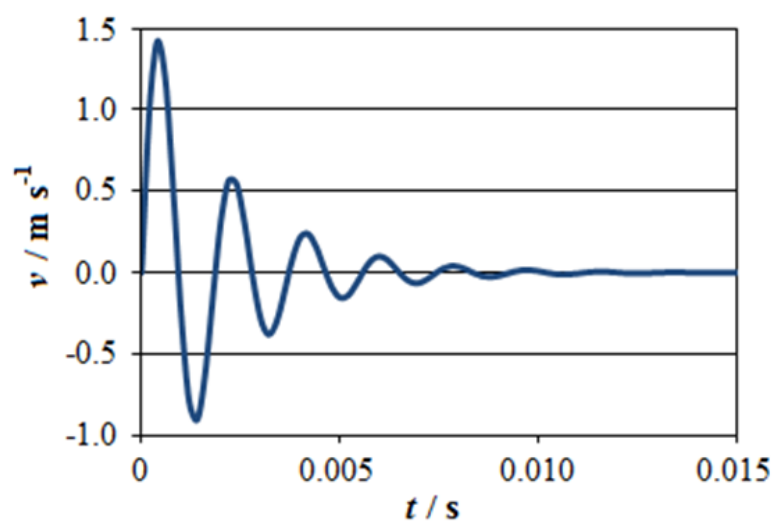

Figure 9. Time dependence of velocity of slide valve of pressure reduction valve.

The time dependencies of the input pressure $p_{1}$ (see figure 10) and the output flow $Q$ (see figure 11) are derived from the Eqs. (28) and (12):

$$
\begin{gathered}
p_{1}=\frac{1}{Z_{v}+Z_{T}} \cdot\left(S_{T} \cdot x+Z_{v} \cdot p_{2}+S \cdot \frac{d x}{d t}\right) . \\
Q=Z_{v} \cdot\left(p_{1}-p_{2}\right)-S \cdot \frac{d x}{d t} .
\end{gathered}
$$

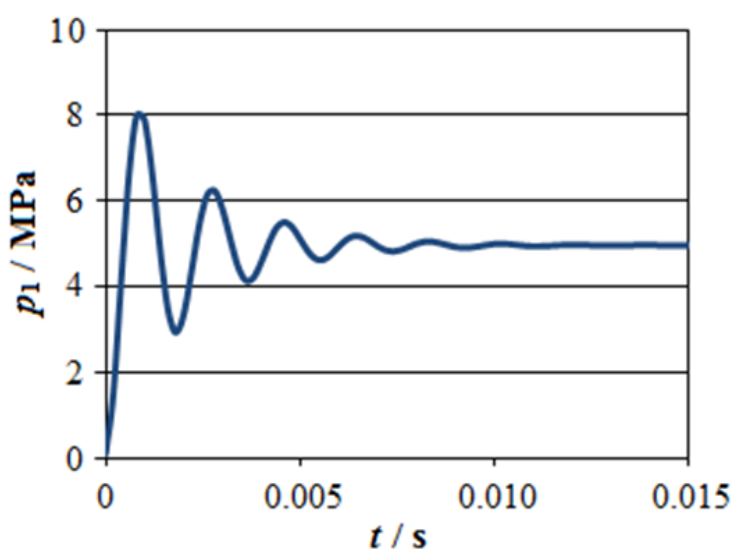

Figure 10. Time dependence of input pressure.

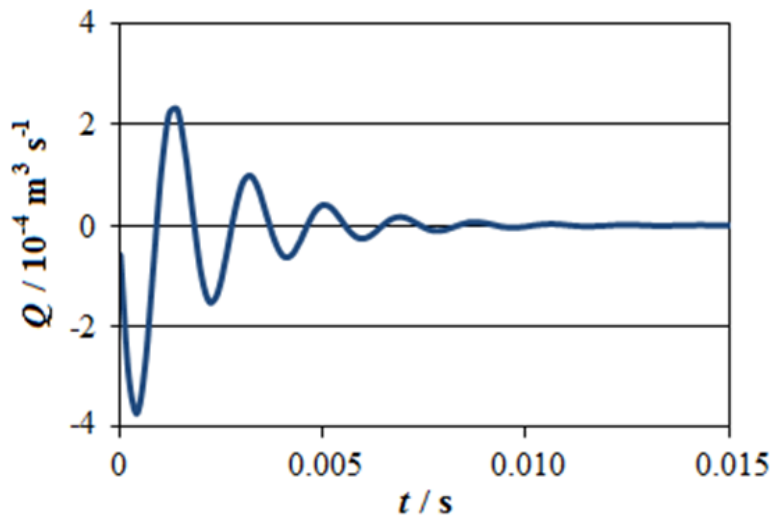

Figure 11. Time dependence of output flow.

It is obvious (see figure 10), that the input pressure increment $\Delta p_{1}$ is practically same as the step change of the output pressure (i.e. $\Delta p_{1} \cong \Delta p_{2}=5 \mathrm{MPa}$ ). For this reason the pressure gradient through the proportional distributor is practically independent of a motor load:

$$
\Delta p_{v}=p_{1}-p_{2} \cong \text { const. }
$$

Then the flow $Q$ is also independent (see figure 11) of the motor load (see Eq. (1)). It is a big advantage of three-way throttle valves with pressure gradient stabilization compared to ordinary throttle valves.

It is again evident (see figure $8 \div$ figure 11 ), that the time dependencies of the simulated quantities are damped periodic with the eigenfrequency $f_{0} \cong 555.6 \mathrm{~Hz}$.

\subsubsection{Determination of eigenfrequency by Laplace transformation}

After Laplace transforming, the Eqs. (27) and (28) are modified as follows:

$$
\begin{gathered}
m \cdot s^{2} \cdot X(s)+b \cdot s \cdot X(s)+k \cdot X(s)= \\
=\left(P_{2}(s)-P_{1}(s)\right) \cdot S \\
0=-S_{T} \cdot X(s)-Z_{v} \cdot P_{2}(s)+ \\
+\left(Z_{v}+Z_{T}\right) \cdot P_{1}(s)-S \cdot s \cdot X(s) .
\end{gathered}
$$

The transfer function $F_{X P 2}$ is expressed by the ratio of the Laplace image $X(\mathrm{~s})$ of the slide position and the Laplace image $P_{2}(\mathrm{~s})$ of the output pressure. It is determined from the Eqs. (33) and (34):

$$
F_{X P_{2}}(s)=\frac{X(s)}{P_{2}(s)}=\frac{Z_{T} \cdot S}{S^{2} \cdot s+S_{T} \cdot S+\left(Z_{v}+Z_{T}\right) \cdot\left(m \cdot s^{2}+b \cdot s+k\right)} .
$$

It is evident that the denominator forms of the Eqs. (25) and (35) are aqual. For this reason the eigenfrequency of the three-way throttle valve with pressure gradient stabilization is the same as in the previous case, i.e. $f_{0}=538.26 \mathrm{~Hz}$. 


\section{Conclusions}

The purpose of the paper was to investigate dynamical behaviour and eigenfrequency of three-way throttle valve with pressure gradient stabilization. It was performed for two different transient changes, specifically for step change in position of the slide valve of the proportional distributor and for step change of a motor load.

The eigenfrequency was determined by two different methods, i.e. using Mathcad software and by Laplace transformation. It was found by the two methods that the eigenfrequency of the three-way throttle valve with pressure gradient stabilization is very high (i.e. $\left.f_{0}=538.26 \mathrm{~Hz}\right)$ in this case. These methods are advantageous mainly from time and financial point of view compared to experimental measurements. They also allow to simulate different working states of hydraulic systems. For the above-mentioned reasons these methods are frequently applied at the present time.

Throttle valves (including the three-way throttle valve with pressure gradient stabilization) have important functions in hydraulic systems too. They have an additional damping effect during transient changes of systems. They are used to elimination of oscillations in hydraulic systems. For this reason it is suitable to locate the throttle elements closest to hydraulic consumers because hydraulic motor in conjunction with hydraulic line create a mechanical oscillating system. It was also verified that liquid flow through the three-way throttle valve with pressure gradient stabilization is independent on load changes of a hydraulic motor. For this reason the speed (or the velocity) of the hydraulic motor is practically constant and independent on the motor load. It is a big advantage of these valves compared to ordinary throttle valves. Furthermore the efficiency of hydraulic systems with three-way throttle valves is higher compared to hydraulic systems that are controlled by ordinary throttle valves.

\section{References}

1. H. Exner, R. Freitag, H. Geis, R. Lang, J. Oppolzer, P. Schwab, E. Sumpf, R.A. Lang, The Hydraulic Trainer Volume 1 - Basic Principles and Components of Fluid Technology (Mannesmann Rexroth GmbH, Lohr am Main, 1991)

2. H. Dörr, R. Ewald, J. Hutter, D. Kretz, F. Liedhegener, A. Scmidt, The Hydraulic Trainer Volume 2 - Proportional and Servo Valve Technology (Mannesmann Rexroth GmbH, Lohr am Main, 1986)

3. M. Vašina, Energy saving hydraulic systems of lifting and loading equipment mounted on lorries (VŠB - Technical University of Ostrava, Czech Republic, 2000)

4. Mannesmann Rexroth $\mathrm{GmbH}$, (catalog sheets)

5. P. Dudek, Mathcad - User's Guide (Grada, Prague, 1992)

6. P. P. Valkó, L. Abate, Computers \& Mathematics with Applications 48, 3-4 (2004)

7. F. Durbin, Computer Journal 17, 4 (1974)
8. J. Rommes, N. Martins, IEEE Transactions on Power Systems 21, 3 (2006)

\section{Acknowledgements}

This paper has been elaborated in the framework of the project Opportunity for young researchers, reg. no. CZ.1.07/2.3.00/30.0016, supported by Operational Programme Education for Competitiveness and cofinanced by the European Social Fund and the state budget of the Czech Republic.

The work presented in this paper was also supported by a grant SGS "Zkoumání dynamiky hydraulického vedení" SP2014/208. 